\title{
The modelling of an anoxic-aerobic biological reactor
}

\author{
S. R. M. Kutty ${ }^{1}$, H. A. Gasim ${ }^{2} \&$ M. H. Isa ${ }^{1}$ \\ ${ }^{1}$ Department of Civil Engineering, Universiti Teknologi PETRONAS, \\ Malaysia \\ ${ }^{2}$ Department of Civil Engineering, Universiti Tenaga Nasional, Malaysia
}

\begin{abstract}
The anoxic-aerobic wastewater treatment process increases wastewater treatment efficiency and decreases the aeration basin. In this study, raw data obtained from two anoxic-aerobic biological reactors (AABR) used for the treatment of different loads of petroleum refinery wastewater (PRW) were used for developing a mathematical model that could simulate the process trend. The data consists of 160 entries and was gathered over approximately 180 days from two AABR reactors that were continuously operated in parallel. Two configurations of artificial neural networks were compared and different numbers of neurons were tested for an optimum model that could represent the process behaviour under different loads. The tangent sigmoid transfer function (Tansig) at the hidden layer and a linear transfer function (Purelin) at the output layer with 9 hidden neurons were selected as the best optimum model. From the simulation model, the highest removal efficiency was observed as $96 \%$, which was recorded for chemical oxygen demand (COD) influent concentration of $3150 \mathrm{mg} / \mathrm{L}$. Effluent concentration below $100 \mathrm{mg} / \mathrm{L}$ was recorded for influent COD concentration, which ranged between 150 and $700 \mathrm{mg} / \mathrm{L}$ corresponding to the removal efficiency in the range of $78-88 \%$.

Keywords: anoxic, aerobic, biological treatment.
\end{abstract}

\section{Introduction}

The petroleum refineries discharge large amounts of petroleum refinery wastewater (PRW) with hazardous constituents [1] that are difficult to degrade. High concentrations of phenol, oil and grease, and ammonia were observed in 
water and sediment at the point of effluent discharge due to accumulation over long period of time [2]. These toxic products are with potentially serious consequences on the receiving environment and ecosystem [3]. Treatment of refinery wastewater is normally complex, costly and involved processes to remove organic compounds and other hazardous substances. The treatment includes in-plant source control, pretreatment, and end-of-pipe treatment [4].

Anoxic condition degrades recalcitrant compounds and the volatile organic compounds (VOCs) as well as the compounds that could be stripped during aeration [5]. Researchers have found that benzene, toluene, ethylbenzene and xylene (BTEX) in addition to other compounds can be biodegraded using nitrate as electron acceptor in anoxic condition [6]. Complete removal of BTEX in anoxic-microaerobic-aerobic condition could be achieved [7]. Under anoxic condition $1050 \mathrm{mg} / \mathrm{l}$ of phenol at $6 \mathrm{hr}$ cycle length $\left(6.4 \mathrm{~kg} \mathrm{COD} / \mathrm{m}^{3} \cdot \mathrm{d}\right)$ could be removed up to $80 \%$ [8]. A wide range of toxic organic compounds found in petroleum refinery wastewater have been found to serve as growth substrates for aerobic bacteria [9]. Almost all petroleum hydrocarbons are biodegradable under aerobic conditions, but in many cases when dissolved hydrocarbon is greater than 2 to $4 \mathrm{mg} / \mathrm{L}$, biodegradation may be incomplete [10], and volatilization due to aeration will occur [7]. Aerobic sequencing batch reactor (SBR) treated a synthetic wastewater with a $1300 \mathrm{mg} / \mathrm{L}$ phenol concentration; the 4-hr cycle SBR operation achieved 97\% removal efficiency [11]. Artificial neural networks (ANN) is a modeling tool used to simulate complex relationships through a large number of highly interconnected processing elements (neurons); and has been used in application of artificial intelligence in engineering, pattern recognition and analysis [12]. Chemical oxygen demand (COD) removal was modeled using ANN in a treatment for the prediction and simulation of degradation. Tan sigmoid activation function was used for the input and hidden layers, while the linear activation function was used in the output with 14 neurons, predicted the actual experimental results with correlation coefficient $\left(\mathrm{R}^{2}\right)$ of 0.997 [13]. Using the same mentioned configuration $\mathrm{ANN}$ has being used to simulate full working wastewater treatment plant using data for ten months resulted in $\mathrm{R}^{2}$ values ranged from 0.63 to 0.81 for biochemical oxygen demand (BOD), and from 0.45 to 0.65 for suspended solids (SS) [12]. As petroleum refineries discharge requires advanced multiple treatments; improving treatment system performance in terms of better effluent quality, cost effectiveness, and to cope with the current development of technology, the search for alternative treatment methods is required [14]. The goal of this study was to develop a performance simulation mathematical model for the anoxic-aerobic biological reactor (AABR) using artificial neural network (ANN).

\section{Methodology}

\subsection{Materials and method}

The wastewater for this study was collected from a local petroleum refinery facility that discharges its treated effluent to the sea. The refinery processes 
Malaysian light, sweet crude oil and also includes a condensate splitter unit for naphtha condensates. The PRW was pretreated in anaerobic reactor before post treated in the AABR. The AABR configuration set up is illustrated in the following Figure 1.

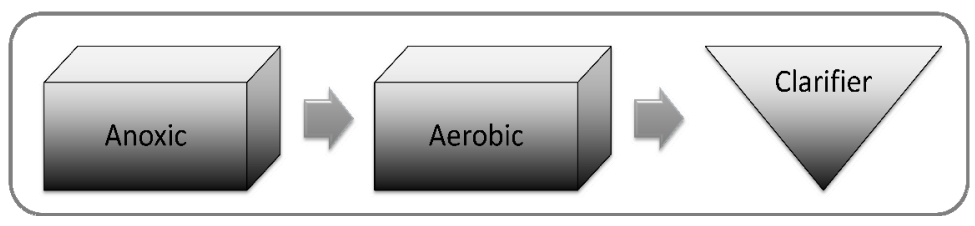

Figure 1: $\quad$ Schematic diagram of the AABR.

\subsection{ANN procedure}

A feed-forward backpropagation network type was selected as optimal generalization was targeted from this tool, and Levenberg-Marquardt backpropagation algorithm (TRAINLM) was used as training function as it is usually able to have smaller mean square error (MSE) compared to other backpropagation algorithms [13] and has been proved to be the fastest and most robust [12]. Batch gradient descent with momentum backpropagation algorithms (LEARNGDM) was used in this study as adaption learning function. The number of neurons has to be determined as it is related to the converging performance of the output error function during the training process. Increasing the number of neurons usually results in a better learning performance, as too few number of neurons limit the ability of the neural network to model the process, but too many number of neurons may result in losing the generalization and learning the noise present in the database used in training [15].

Neural Network in MATLAB (R2009a) software was used with feed-forward backpropagation neural network three layers. There are several activation functions in MATLAB, but few of them were preferable and used in wastewater treatment modeling with low error level [16], namely, sigmoid (hyperbolic tangent and logarithmic) [12] and linear (Purelin) [17]. Two configurations were compared to each other, the first, with log sigmoid transfer function (Logsig) at hidden layer and a linear transfer function (Purelin) at output layer. The second, with tangent sigmoid transfer function (Tansig) at hidden layer and a linear transfer function (Purelin) at output layer. The linear activation function (Purelin) was used for both configurations for the output neuron since it is appropriate for continuous valued targets [12]. The set of data obtained from the impact of different organic loads was used in the modeling. The data covered approximately 180 days and with 160 entries for input and output. Half of the data were used to train the model and the other half was used for validation. The data were organized by selecting the single entries in term of order as training set and even entries in term of order as validation set. Normalization of input data was performed by dividing all the input data with the maximum input; this resulted in the data to be in the range of 0 to 1 . Target data were normalized by 
dividing all the output data with the maximum output; this resulted in the data to be in the range between 0 and 1 . Neurons were tested and varied the number of neurons in the range from 5 up to 35 neurons. The random initialization produces different results; hence, for better initialization of the model, the model was run 100 times at every neuron tested. The optimum number of neurons of the training set was determined based on: minimum root mean square error (RMSE), maximum variance accounted for (VAF), maximum correlation coefficient $\left(\mathrm{R}^{2}\right)$ and minimum mean absolute percentage error (MAPE).

\section{Result and discussions}

The AABR was modeled using artificial neural networks software. LogsigPurelin transfer function was compared to Tansig-Purelin transfer function to define the optimum model. The selected model was then used to predict the reactor performance.

\subsection{ANN modelling results}

During testing and validation of data, number of neurons was tested ranging from 5 to 35. Table 1 below shows the number of neurons tested and the score registered for RMSE, VAF, $\mathrm{R}^{2}$ and MAPE during evaluation of Logsig-Purelin, and Tansig-Purelin transfer functions.

Although the number of neurons are in the range of 5-35, but from Figure 2 it was noted that after neuron 10 and from plotted line representing the $\mathrm{R}^{2}$ from the training set is losing similarity with $\mathrm{R}^{2}$ from validation set, indicating over fitting and the model will not be able to generalize the pattern of the data that used as training set during validation [18].

Thus, the number of neurons was limited to the range between 5-10 neurons, and the optimum neuron was selected as shown in Table 1 based on minimum RMSE, maximum VAF, maximum $\mathrm{R}^{2}$ and minimum MAPE. Both LogsigPurelin and Tansig-Purelin transfer function indicated 9 neurons is the optimum. $\mathrm{R}^{2}$ in Tansig-Purelin was slightly higher and all four parameters were closer. Thus, tangent sigmoid transfer function (Tansig) at hidden layer and a linear transfer function (Purelin) at output layer with 9 neurons is the optimum transfer function. Figure 3 showed the measured experimental data and the predicted using ANN for eighty entries of data that were used for training. Figure 4 showed the measured experimental data and the predicted using ANN for eighty entries of data that were used for validation. The best selected model shows significant prediction of actual experiment based on minimum RMSE, maximum VAF, maximum $\mathrm{R}^{2}$ and minimum MAPE; hence, it was then used for simulation.

\subsection{ANN simulation results}

The best model with Tansig-Purelin transfer function and 9 neurons was used to simulate random data to find out the optimum efficiency. Figure 5 shows all the hundred and sixty data set that was used for both the training and validation, used here for simulation. 
Table 1: $\quad$ Number of neurons tested and the score for evaluation parameters for AABR.

\begin{tabular}{|l|l|l|l|l|l|l|l|l|}
\hline \multirow{2}{*}{ Neurons } & \multicolumn{4}{|l}{ Logsig-Purelin } & \multicolumn{4}{l|}{ Tansig-Purelin } \\
\cline { 2 - 9 } & RMSE & VAF & $\mathrm{R}^{2}$ & MAPE & RMSE & VAF & $\mathrm{R}^{2}$ & MAPE \\
\hline 5 & 0.089 & 82.935 & 0.828 & 16.001 & 0.088 & 83.277 & 0.832 & 15.248 \\
\hline 6 & 0.088 & 83.363 & 0.833 & & 0.084 & 84.853 & 0.848 & 15.460 \\
\hline 7 & 0.086 & 83.941 & 0.839 & 15.420 & 0.087 & 83.826 & 0.838 & 15.541 \\
\hline 8 & 0.086 & 84.241 & 0.842 & 15.720 & 0.084 & 84.851 & 0.848 & 15.164 \\
\hline 9 & $\mathbf{0 . 0 8 3}$ & $\mathbf{8 5 . 6 1 0}$ & $\mathbf{0 . 8 5 2}$ & 15.107 & $\mathbf{0 . 0 8 3}$ & $\mathbf{8 5 . 2 7 0}$ & $\mathbf{0 . 8 5 3}$ & 15.540 \\
\hline 10 & 0.084 & 84.904 & 0.849 & 15.197 & 0.083 & 85.064 & 0.850 & $\mathbf{1 5 . 0 7 6}$ \\
\hline
\end{tabular}
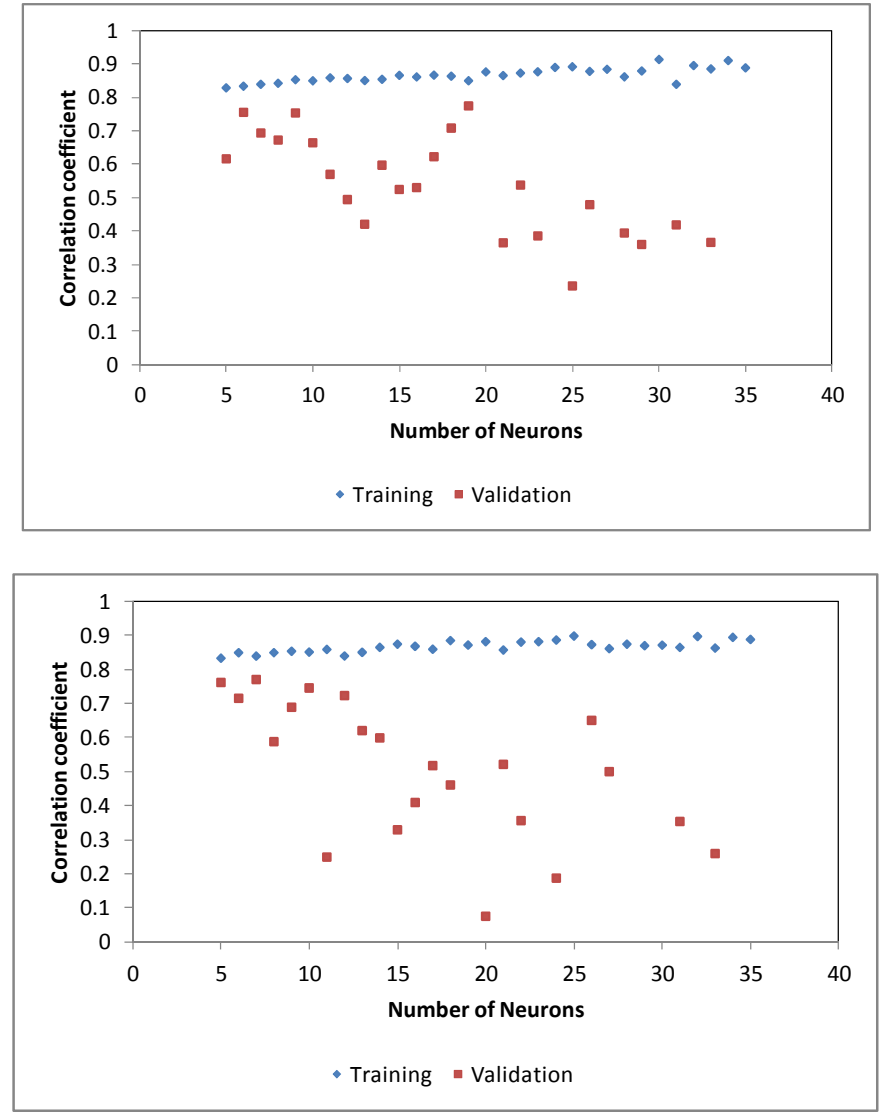

Figure 2: $\quad \mathrm{R}^{2}$ scores versus number of neurons tested for Logsig-Purelin and Tansig-Purelin transfer functions for AABR. 

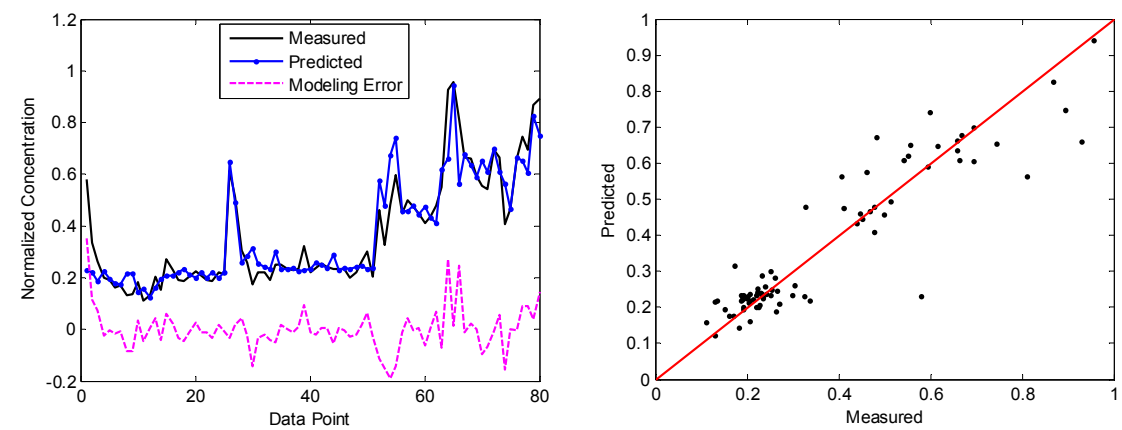

Figure 3: $\quad$ AABR measured and predicted normalized data for training set.
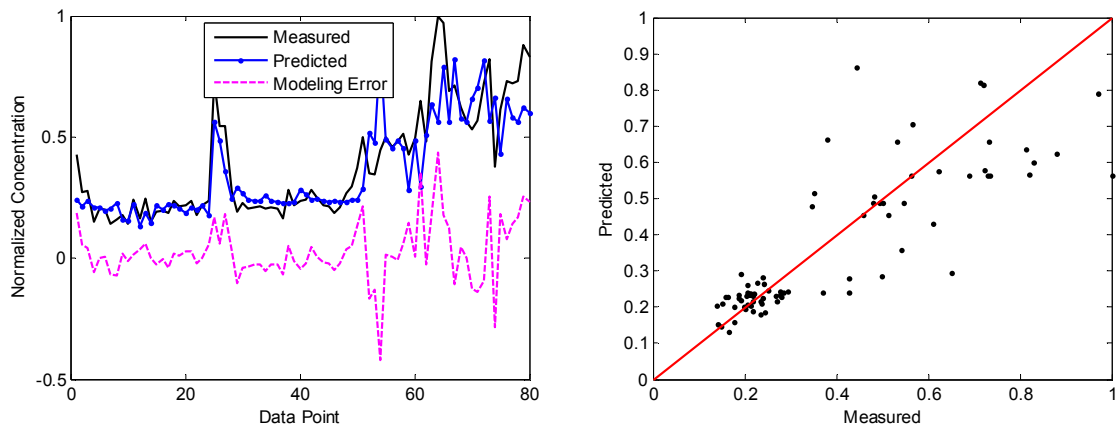

Figure 4: AABR measured and predicted normalized data for validation set.
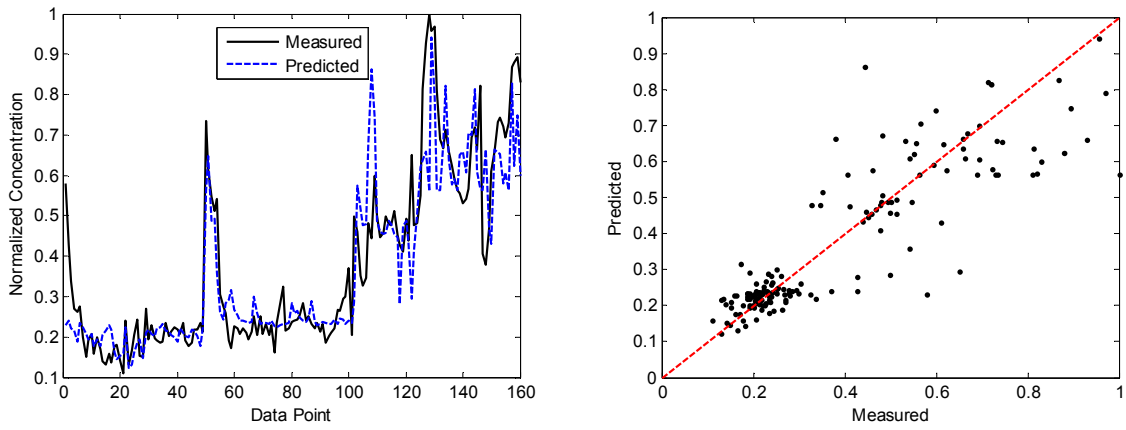

Figure 5: AABR measured and predicted normalized data for actual data simulation. 
Random data entries ranged from 150 to $4800 \mathrm{mg} / \mathrm{L}$ was used as influent to simulate the reactor performance; Figure 6 shows the simulated influent and effluent concentrations in addition to removal efficiency. Highest removal efficiency observed was $96 \%$ recorded and was recorded at influent $3150 \mathrm{mg} / \mathrm{L}$, while the corresponded effluent concentration was $115 \mathrm{mg} / \mathrm{L}$. Effluent concentration below $100 \mathrm{mg} / \mathrm{L}$ was recorded for influent concentration ranged between $150-700 \mathrm{mg} / \mathrm{L}$ corresponding to removal efficiency in the range of $78-88 \%$.

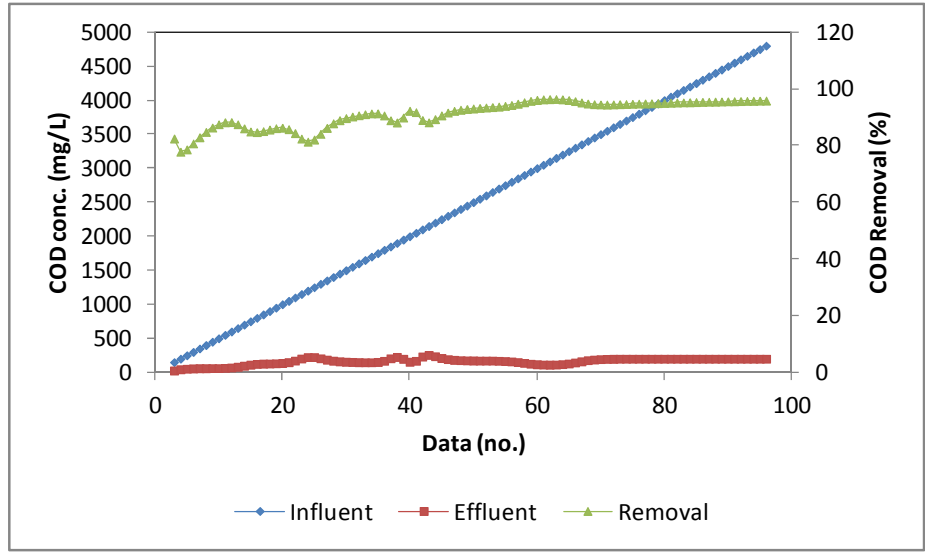

Figure 6: AABR effluent concentration and removal efficiency versus influent concentration using best selected model for Tansig-Purelin transfer function.

\section{Conclusions}

Modeling the data obtained from the anoxic-aerobic biological reactor under various loads, resulted in a model that used tangent sigmoid transfer function (Tansig) at hidden layer and a linear transfer function (Purelin) at output layer with 9 neurons as the optimum transfer function. Simulation using the optimum model with random data entries ranged between 150 to $4800 \mathrm{mg} / \mathrm{L}$ as influent, resulted in a pattern that simulate the reactor performance for data that were never really experimentally tested in the lab. Lab experiment was showing highest removal of $89 \%$ and could not define the exact load that can give effluent concentration below $100 \mathrm{mg} / \mathrm{L}$; but from the simulation model, $96 \%$ removal efficiency was recorded for $3150 \mathrm{mg} / \mathrm{L}$, and loads that can give concentration below $100 \mathrm{mg} / \mathrm{L}$ were defined.

\section{Acknowledgement}

This work was supported by the Universiti Teknologi PETRONAS graduate assistantship scheme. 


\section{References}

[1] Suleimanov, R.A., 1995. Conditions of waste fluid accumulation at petrochemical and processing enterprises and prevention of their harm to water bodies. Meditsina Truda I Promyshlennaia Ekologiia, 12, 31-36.

[2] Otokunefor, T.V. \& Obiukwu, C., 2005. Impact of refinery effluent on the physicochemical properties of a water body in the Niger delta. Applied ecology and environmental research, 3, 61-72.

[3] Beg, M.U., Al-Muzaini, S., Saeed, T., Jacob, P.G., Beg, K.R., Al-Bahloul, M., Al-Matrouk, K., Al-Obaid, T. \& Kurian, A., 2001. Chemical contamination and toxicity of sediment from a coastal area receiving industrial effluents in Kuwait. Arch Environ Contam Toxicol, 41, 289-97.

[4] Wang, L.K., Hung, Y.-T., Lo, H.H. \& Yapijakis, C., 2006. Treatment of oilfield and refinery wastes. Waste Treatment in the Process Industries. Boca Raton: CRC Press.

[5] Ma, G. \& Love, N.G., 2001b. Creating anoxic and microaerobic conditions in sequencing batch reactors treating volatile BTX compounds. Water Sci Technol, 43, 275-282.

[6] Bush, K.E., 1980. Refinery wastewater treatment and reuse. Industrial Wastewater and Solid Waste Engineering. New York: McCraw-Hill Publications Co.

[7] Ma, G. \& Love, N.G., 2001a. BTX biodegradation in activated sludge under multiple redox conditions. Journal of Environmental Engineering, 127, 509-516.

[8] Sarfaraz, S., Thomas, S., Tewari, U.K. \& Iyengar, L., 2004. Anoxic treatment of phenolic wastewater in sequencing batch reactor. Water Res, 38, 965-971.

[9] Metcalf, L. \& Eddy, H., 2003. Wastewater engineering, treatment, disposal and reuse, New York, McGraw Hill.

[10] Norris, R.D., 1995. In-situ bioremediation of ground water and geological material: A review of technologies, DIANE Publishing.

[11] Yoong, E.T. \& Lant, P.A., 2001. Biodegradation of high strength phenolic wastewater using SBR. Water Sci Technol, 43, 299-306.

[12] Hamed, M.M., Khalafallah, M.G. \& Hassanien, E.A., 2004. Prediction of wastewater treatment plant performance using artificial neural networks. Environmental Modelling and Software, 19, 919-928.

[13] Elmolla, E.S., Chaudhuri, M. \& Eltoukhy, M.M., 2010. The use of artificial neural network (ANN) for modeling of COD removal from antibiotic aqueous solution by the Fenton process. J Hazard Mater, 179, 127-134.

[14] Rahman, M.M., 2004. Treatment of petroleum refinery wastewater using Crossflow Membrane Bioreactor (CF-MBR). Master of Science, King Fahd University of Petroleum \& Minerals (KFUPM).

[15] Holubar, P., Zani, L., Hager, M., Froschl, W., Radak, Z. \& Braun, R., 2002. Advanced controlling of anaerobic digestion by means of hierarchical neural networks. Water Res, 36, 2582-258. 
[16] Tezel, G., Yel, E. \& Sinan, R.K., Artificial neural network (ANN) model for domestic wastewater treatment plant control. The Fourth International Scientific Conference on Water Observation and Information System for Balkan Countries, 2010 Ohrid. Balwois.

[17] Jami, M.S., Husain, I.A.F., Kabashi, N.A. \& Abdullah, N., 2012. Multiple inputs artificial neural network model for the prediction of wastewater treatment plant performance. Australian Journal of Basic and Applied Sciences, 6, 62-69.

[18] Jeon, J.K. \& University, N.C.S., 2007. Fuzzy and neural network models for analyses of piles, Ann Arbor, North Carolina State University. 